\title{
ALGUNOS COMENTARIOS CRÍTICOS SOBRE EL LIBRO HABLAR CON CORRECCIÓN, DE PANCRACIO CELDRÁN GOMARIZ
}

\author{
Víctor M. LONGa y JuAn J. López Rivera \\ Universidade de Santiago de Compostela \\ victormanuel.longa@usc.es, juanjose.lopez.rivera@usc.es
}

\begin{abstract}
Otro sueño fundamental [...] es el del derecho que tenemos, en una verdadera democracia, a ser diferentes, y en razón de ese derecho, su extensión en el derecho a ser respetados en la diferencia (Freire, 1993: 29)
\end{abstract}

Como es bien sabido, las lenguas distan mucho de ser entidades homogéneas; al contrario, en el seno de cada una existe mucha variación (social, geográfica, etc.) que supone una gran riqueza. El colectivo de lingüistas suele ser muy respetuoso con esta variación: abiertamente cuando se trata de hacer declaraciones de principios; no siempre, en cambio, cuando lo que corresponde es hacer de aquéllas práctica de investigación. Por ello, lo común es adoptar ante la variación una posición no prescriptiva (esto es, descriptiva), que considera que todas las variantes internas de una lengua están en el mismo plano de igualdad: «linguists take language as they find it, rather than attempting to regulate it in the direction of preconceived criteria» (Fasold y Connor-Linton, 2006: 7-8). De ahí se sigue que, desde una óptica lingüística, «the use of language by educated people is not considered either more or less significant than usage by less educated people» (Fasold, 2006: 379). En consecuencia, la profesión lingüística asume que cualquier variedad no es ni más ni menos correcta, ni superior ni inferior, a cualquier otra, teniendo cualquier dialecto (sea geográfico o social) el mismo valor que el resto de ellos.

Sin embargo, por desgracia no es esa visión de la variación intralingüística como riqueza la única existente; de hecho, la creencia mayoritaria sobre tal variación implica considerar que parte de ella es 'correcta' o 'superior', mientras que el resto es 'incorrecta', 'inferior' o incluso 'degenerada'. El ejemplo más diáfano de tal situación lo constituye la variedad estándar de una lengua, muy sobrevalorada frente al resto de variedades. Este estado de cosas es especialmente activo en Europa Occidental ${ }^{1}$, e implica que la variedad estándar acaba marginando y en gran medida invisibilizando a las otras variedades, con lo que éstas, en vez de ser apreciadas como un rico acervo o patrimonio lingüístico, pasan a juzgarse como una rémora para el idioma. Tal concepción resulta de una construcción ideológica que supone

1 No por casualidad, señala Romaine (1994: 107) que la normalización lingüística y el estándar son invenciones europeas. 
identificar una lengua con su estándar (cf. Moreno Cabrera, 2008)2 ${ }^{2}$ En palabras de SchillingEstes (2006: 312):

Many people equate the term 'language', as in 'the English language' or 'the French language' with the Standard language, that is, that version of the language held to be correct in pedagogical grammar books and usage guides and used in education, the workplace, and the government. Because the standard is associated with education and sophistication, other varieties are often considered to be lesser versions of the language -perhaps not as fully formed, or maybe 'sloppy' in comparison with the standard.

Y eso implica que la infravaloración de las variedades no estándares es transferida a quienes las emplean, acusados de hablar mal, incorrectamente, o incluso de no saber hablar.

Como hemos señalado, lamentablemente, la idea de que las variedades no estándares son inferiores al estándar está muy extendida ${ }^{3}$. La delimitación de qué es correcto o qué no lo es se efectúa atendiendo exclusivamente a lo que pertenece o no al estándar, por lo que éste se erige en el modelo único sobre el que se juzga, y en consecuencia es tomado como referencia exclusiva de lo que se debe decir. Por tanto, tal perspectiva purista o prescriptiva se caracteriza por la imposición, ya que establece «reglas prácticas sobre el uso correcto del lenguaje, con el fin de mantener su unidad o su pureza» (Alcaraz Varó y Martínez Linares, 1997: 170). Tal posición, pues, establece juicios de valor sobre diferentes variedades, dividiéndolas en correcta (el estándar) e incorrectas, instando a seguir la primera. Por ello, sostiene una profunda desigualdad entre las diferentes variedades, menospreciando a las diferentes del estándar. Pero la consecuencia más grave de tal postura no es tachar una variedad de incorrecta; dado que cualquier variedad no existe en el vacío, sino que es usada por personas, esa postura desemboca inevitablemente en la discriminación, en marginar a las personas que utilizan esas variedades no estándares (cf. infra). Al cabo, la posición prescriptiva no agota su actuación en el dominio lingüístico, sino que apunta también a una prescripción que pretende trabajar sobre el ordenamiento social de modo jerarquizante y profundamente antidemocrático.

Los autores de este trabajo creemos que, como cualquier otra persona que desempeñe cualquier otra profesión, el colectivo de lingüistas debe tener un compromiso social, una responsabilidad ante la sociedad, responsabilidad que, entre otros aspectos, supone mostrar que ciertas ideas, como las relativas a la corrección e incorrección en el lenguaje (superioridad e inferioridad de variedades lingüísticas), son meros prejuicios, ideas infundadas y carentes de cualquier base o sustento desde una óptica puramente lingüística, y que propician la discriminación (de variedades o, por encima de todo, de hablantes).

Y decimos esto porque lo más grave de la situación mencionada consiste en que tales ideas no se producen solo en gente que carece de formación lingüística, sino también en otras de las que no se esperaría ese tipo de juicios (temerarios) de valor, por ser personas (en algunos casos, filólogos, como sucede con el autor del libro que suscita esta nota, y en otros,

2 Nótese, como señala Joseph (2006: 29), que, en cuanto surge el estándar, surge al tiempo el mito de que ese estándar es la forma verdadera y única de la lengua en cuestión.

3 Una buena prueba de cuán ampliamente tal perspectiva impregna la sociedad es la existencia de secciones regulares dentro de los medios de comunicación, como la radio (podemos citar en este sentido «Los vigilantes del idioma» en el programa «Hoy por hoy» de la SER, o la sección del propio Pancracio Celdrán Gomariz en el programa «No es un día cualquiera» de RNE). 
incluso lingüistas) que supuestamente deberían conocer el fenómeno lingüístico como para no caer en tales opiniones y así no azuzar al resto de la sociedad. En este sentido, muchos trabajos sostienen esa concepción que iguala el estándar con 'hablar bien' y que estigmatiza todos aquellos rasgos no inscritos en él, presentándolos, por citar un breve florilegio, como «rasgos que deterioran nuestro sistema de comunicación» (Lázaro Carreter, 1997: 26), «desmanes» (Lázaro Carreter, 2003: 26), «desviaciones» (Gómez Torrego, 2002: 7) y que llegan incluso a afirmaciones tan extremas como la de Grijelmo (2006: 21): «La vulneración de ese sistema [el estándar; VML y JJLR] produce supuraciones [...] Esas supuraciones no suelen ser graves, pero muestran generalmente algún problema que, si no se atiende, puede degenerar en una infección mayor que afecte incluso al pensamiento». En todos estos casos, pues, se identifica la gramática del español con la del español estándar, con lo que se comete la falacia de identificar una parte (el estándar, y que deriva además en gran medida de una construcción artificial; cf. Moreno Cabrera, 2008) con el todo (lengua española).

En este contexto, Pancracio Celdrán Gomariz (en adelante, PCG) se puede considerar como el verdadero abanderado de la perspectiva prescriptiva o purista, al ser su libro Hablar con corrección (Celdrán Gomariz, 2006) un ejemplo ciertamente extremo de ella: no solo porque está lleno de prejuicios en su contenido, sino por su tono muy agresivo, abundando expresiones absolutamente irrespetuosas hacia lo no estándar (y, por extensión, hacia los hablantes de esas variedades, que son discriminados). Sencillamente, el respeto brilla por su ausencia, y no solo en lo que concierne al lenguaje, sino a otro tipo de juicios completamente desafortunados.

Decíamos que PCG bien pudiera ser tomado como uno de los más extremos (e intolerantes) ejemplos de la perspectiva purista. Como es bien sabido, la Real Academia Española suele considerarse (con toda la razón) como el adalid del purismo lingüístico. Sin embargo, no lo es suficientemente a juicio del autor del libro, quien critica en diferentes ocasiones a tal institución al entender que ésta ha efectuado concesiones inadmisibles ante rasgos 'vulgares', por lo que sugiere que la RAE está degenerando, o sucumbiendo ante el influjo del 'mal hablar' (lo cual, por descontado, no deja de ser irónico). Algunos ejemplos ilustran tal aspecto:

- Por ejemplo, sobre la acentuación de formas latinas, PCG escribe que «Hay que ser disciplinados, seguir una norma, no saltarse las costumbres y usos ortográficos de siempre a la torera, actitud en la que parece andar involucrada la antaño Docta Casa» (p. 57).

- Sobre el uso del género 'común', plasmado en piezas léxicas como 'general', 'concejal', etc. PCG señala que es tan descabellado 'concejala' como 'generalo', «pero todo se andará [...]: tanto irá el cántaro a la fuente hasta que se rompa, en cuyo caso el disparate será bendecido por la Docta Casa» (p. 77).

- Como último ejemplo, el autor tacha de vulgarismo el uso del verbo 'coger' con el significado de 'caber', «aunque la Academia lo admite sin hacer reserva alguna» (p. 96).

Como se aprecia, el autor no deja en muy buen lugar a la $\mathrm{RAE}^{4}$, lo cual, por otro lado, no nos preocupa demasiado, si bien ilustra la perspectiva 'prusiana' del libro. De ahí

4 El que la RAE haya hecho o no dejación de sus funciones es asunto que seguramente merecería mayor discusión y denuedo en su demostración del que acredita PCG. Lo cierto es que dar por corroborada esa renuencia abre la 
nuestra anterior denominación del autor como uno de los máximos abanderados del purismo lingüístico.

La obra está dirigida «a la ciudadanía que ve cómo, día a día, el empobrecimiento del idioma avanza tornándose preocupante» (p. 12), de manera que el propósito de PCG es «salir al encuentro de esa ola gigante de mal decir» (p. 12). Más extensamente, señala el autor al respecto que:

El dequeísmo avanza; los idiotismos del lenguaje proliferan al tiempo que la gramática y el léxico se resienten gravemente de estas embestidas y todo se convierte, en el plano del lenguaje, en terreno propicio al solecismo o mal uso de las palabras, falta de sintaxis o cualquier error cometido contra la lengua» (p. 11).

En suma, a su juicio el idioma se rompe y se corrompe. Y su llamamiento a la pureza del idioma se efectúa en términos apocalípticos, algo que en realidad es una constante de las obras que claman por la 'corrección' de la lengua. Como ha mostrado Muro (1990: 3940) en su estudio sobre la cuestión de la normatividad, el discurso usual de los que apelan a la corrección lingüística suele ser imperativo y condenatorio, abundando en él expresiones relacionadas con el derecho penal y la sanción legal (del estilo de 'deben ser proscritos' o 'reciben grave sanción') y asimismo otras expresiones que representan una actitud demasiado vehemente ('vicio', 'lacra', 'agresión', 'peligro', 'delito', 'degeneración', 'corrupción', etc.). La obra comentada no se queda corta en tal tipo de expresiones, algunas de las cuales son «semilla de la incorrección y el disparate» (p. 13), «hablar mal [...] es propio de energúmenos de la cultura» (p. 13), «vicios de dicción» (p. 19) o «vicios» (p. 31), «deformaciones notables» (p. 29), «defectos que se dan en los lenguajes oral y escrito» (p. 32), «contaminar en la mente del hablante la forma que debe recibir» (p. 32), «efecto pernicioso» (p. 33), «papanatismo lingüístico [...] [de] los hispanohablantes» (p. 60), «no resbalar hacia el error» (p. 70), «[acortar palabras] desvirtúa el idioma» (p. 74), «descabellado» (p. 77), «este uso se generalizó y degeneró» (pp. 80 y 121), «práctica errónea que va en aumento» (p.80), «pronunciación viciosa» (p. 83), «barbarismo extremo» (p. 97), «uso anómalo debido al carácter regionalista del hablante» (p. 142) o «casos [...] de papanatismo y seguidismo a ultranza» (p. 190).

Además, no son pocos los llamamientos o mandatos del estilo de «Queridos amigos: ¡cuidado!» (p. 13) o «Hay que ser disciplinados» (p. 57).

Si expresiones como las señaladas no fueran suficientemente claras sobre el desprecio absoluto de la obra por todo lo que se aparta de la variedad estándar, en otras ocasiones esas variedades no estándares son menospreciadas directamente. Tal es el caso, por ejemplo, cuando alude a «formas léxicas chocantes de entendimiento rápido muy propias de una lengua urbana de usar y tirar» (p. 99), o cuando, al respecto de la 'moda' de acortar palabras, que desvirtúa a su juicio el lenguaje, PCG afirma que tiene que ver con la emergencia de 'jergas' juveniles (p. 74). Algo muy semejante sucede cuando el autor se refiere a «casos de

puerta a una serie de autores que se animan, heroicamente (y sin reparar en las pingües ganancias que ello reporta), a «atajar desmanes», «desviaciones» y a poner apósitos de sensatez en las «supuraciones» que están quebrantando el español. Afortunadamente, la lengua española hoy, a lo que parece, abandonada a su suerte por la RAE, ha encontrado nuevos paladines que asumen la tarea de limpiarla, fijarla y darle el esplendor de la que es acreedora. 
uso anómalo debido al carácter regionalista del hablante» (p. 142), donde de nuevo se aprecia claramente que ese 'carácter regionalista' (expresión por otro lado curiosa ${ }^{5}$, más propia de antaño) deriva de que choca con el estándar. Lo que el autor denomina 'lengua de usar y tirar' o 'jerga', la sociolingüística las considera variedades de muy alto interés, tan dignas de ser estudiadas como cualquier otra. Toda lengua o variedad, con excepción de las que envasaría con gusto el prescriptivismo en una burbuja de inmovilidad imperecedera, es de 'usar y tirar', 'usar y cambiar', 'usar y renovar'. No otra cosa es precisamente el uso, el encuentro de la potencia y el acto y los 'actantes' o 'actuantes' ${ }^{6}$ lingüísticos, quienes, imprimiéndoles su huella, mantienen a una lengua con vida.

Además del tono apocalíptico, hay en el libro un no menos claro tono mesiánico, consistente en creer que la gente debe ser guiada para que no quiebre el idioma, dada la asunción, común en el purismo, de que muchas personas no están preparadas por sí mismas para ello. Por ejemplo, eso es lo que sostiene al respecto de muchos integrantes de los medios de comunicación: «unos [...] no ponen la atención debida a cómo transmiten su discurso, y otros [...], aunque la pusieran, serían incapaces de hacerlo con decoro debido a sus muchas limitaciones» (p. 13), o «comentaristas de prensa rosa, gente seguidista y de escasa capacidad de análisis» (p. 175). Más claras aún son estas palabras: «Hay que tomarse en serio estas cosas, [...] de lo contrario se siembra la semilla de la incorrección y el disparate, y la ciudadanía termina por hablar en jerigonza o no saber por dónde se anda» (p. 13). Por tanto, tal concepción considera que las personas son un rebaño que necesita pastores lingüísticos para no 'vender a Cervantes', usando una expresión del propio autor (p. 13) ${ }^{7}$. Y ese aspecto mesiánico es igualmente claro en la letra; por ejemplo, PCG escribe que ha predicado (sic) (p. 12) semana tras semana desde el púlpito de RNE y desde la tribuna de El Semanal, de la cual, por cierto, afirma: «Que os sirvan de ejemplo revistas dominicales como El Semanal, cuyas páginas están pobladas de criaturas sabias [...] que escriben y piensan, y donde la fortuna me ha colocado» (p. 13).

Pero si lo señalado no fuera suficiente, el autor cae muchas veces directamente en el insulto. A este respecto, uno de los epítetos preferidos del autor es "mostrenco"s, usado al menos en

5 Como otras muchas que aparecen en el libro, referidas a muy diferentes aspectos; por ejemplo, sobre el diminutivo escribe que cuando «se aplica al ámbito del amor en el habla íntima inyectada de suavidad hace lascivo y sugerente el discurso» (p. 27).

6 Esta expresión (que no sabemos si llegaría a alcanzar el nihil obstat de PCG) recuerda a otra difundida con profusión en el programa de radio en el que colabora (cf. nota 3). Curiosamente, en «No es un día cualquiera» se rompe con alguna de las denominaciones habituales en el medio (léase 'oyentes') para apostar por alternativas abiertamente innovadoras, como 'escuchantes'.

7 En concreto, escribe PCG que «Hablar mal para hacer gracia es propio de los energúmenos de la cultura que, con tal de arrancar una carcajada, son capaces de vender a Cervantes».

8 La definición que ofrece el DRAE (Real Academia Española, 2001: vol. II, 1544) de tal término, en su segunda acepción, es la siguiente: «Ignorante o tardo en discurrir o aprender», mientras que por su parte el Diccionario de María Moliner (Moliner, 2007: vol. II, 2001) señala que la tercera acepción del mismo término «Se aplica a una persona que, por carente de gracia, torpe, etc., provoca desprecio o enfado». Sigue señalando este diccionario que «Se puede usar en broma»; desde luego, no en el caso de PCG. De todos modos, tal tipo de expresiones es aplicado o no dependiendo de quién cometa lo que PCG considera errores. Por ejemplo, en la p. 143 critica el uso de posesivos en lugar del genitivo, del estilo ‘detrás mía' en lugar de 'detrás de mí', señalando que incluso está presente en escritores tan importantes como Unamuno. Mucho nos tememos que si tal tendencia no fuera plasmada por Unamuno, sino por gente corriente, le aplicaría también el calificativo de 'mostrenco'. 
12 ocasiones, y referido siempre a rasgos no estándares: «uso mostrenco de apariencia seudoculta» (p. 41), «forma mostrenca de expresarse» (p. 53), «la forma mostrenca gana terreno» (p. 58), «usos deformantes y mostrencos» (p. 77), «frase mostrenca» (p. 77-78), «coletillas mostrencas» (p. 79), «elección mostrenca» (p. 97), «coletilla mostrenca» (p. 98), «usos léxicos mostrencos» (pp. 98-99), «uso mostrenco» (p. 159), «intentos mostrencos y esnobistas» (p. 170). El uso de esta expresión que hemos reservado para el final es el más desafortunado (si bien los anteriores no lo son poco); sobre la costumbre de acortar palabras ('peli', 'compa', etc.), el autor escribe que se produce sobre todo en los medios de comunicación, donde, para hacerse los simpáticos, «algunos no sólo se engolfan en esta práctica mostrenca, sino que además pronuncian mal o trastocan los términos creyendo que comunican mejor» (p. 74).

En todo caso, ese no es el único ejemplo donde se traspasan ampliamente los límites de lo razonable; sobre el término 'freak', el autor escribe unas palabras realmente improcedentes, que no nos resistimos a citar:

Es claro que la televisión ha potenciado el gusto por lo cutre, por la basura: paradigma de toda esa lacra son los seudoperiodistas que desde los platós divulgan vociferantes las proezas de chulos y matones, meretrices y proxenetas, mantenidos y mantenidas, maricones y zorras [...]. Hoy abanderan la moda freak personas que ni hicieron cosa de interés ni están capacitadas para hacerlas» (pp. 161-162).

Por otro lado, el autor del libro muestra muy poca sensibilidad (por decir algo) hacia determinados colectivos. Uno de los ejemplos más desafortunados es el tratamiento que efectúa de los homosexuales, cuya denominación en la cita del párrafo anterior (maricones) ilustra perfectamente la opinión que PCG tiene de ellos, al igual que las siguientes palabras (p. 184):

A la persona que prefiere a gente del mismo sexo para ciertas intimidades, si es masculino se le llamó de cien formas a lo largo de nuestra historia lingüística, siendo la menos grave la de «marica» $[. .$.$] . «Marica» [. .$.$] y «maricón» [. .$.$] eran voces descriptivas, ya que para el$ insulto hubo otras de tan grueso calibre como «puto», «sodomita», «bujarrón», «bardaje», según se tratara de sujeto activo o pasivo.

Además de tratar de hacer creer que 'marica' o 'maricón' son meras voces descriptivas (y no profundamente despectivas o denigratorias), y por tanto neutras, para referirse a los homosexuales, es obvio que PCG está aplicando una vara de medir completamente diferente a los homosexuales que la que aplicaría a los heterosexuales; estamos seguros de que si aludiera a una pareja heterosexual, no la definiría nunca como 'los que prefieren a gente de diferente sexo para ciertas intimidades', sino más bien como gente que se quiere, o algo similar. ¿Por qué con respecto a los homosexuales esto debería ser diferente? De ahí el carácter profundamente discriminatorio y reaccionario de alusiones como la comentada9

Esta falta de sensibilidad no impide que PCG se la reconozca en grado máximo a otros grupos humanos tradicionalmente invisibilizados. Llama el autor «hipersensibilidad feminista que nos hace ver peligros por todas partes» (p. 98; cf. también p. 104) a algunos de los

9 Los dardos (y en este caso, no sólo en la palabra) de PCG también alcanzan a fenómenos que se apartan de otras normas homogeneizadoras. Véase, si no, cómo define, al enjuiciar un uso ortográfico concreto, algunas realidades políticas peninsulares: «caso parecido al desmadre que nos invade en las autonomías seudohistóricas» (p. 175). 
intentos que, por la vía de la visibilización lingüística (uso conjunto de 'padres y madres', o de 'ciudadanos y ciudadanas'), intentan afianzar el proceso que persigue un tratamiento social y políticamente igualitario para las mujeres ${ }^{10}$. A este respecto, PCG, al abogar por un uso lingüístico concreto, aprovecha para sugerir que la institución matrimonial es la única idónea para albergar la descendencia (la paternidad, diría el autor); con sus propias palabras, «se dice en castellano «padres» al conjunto del matrimonio con relación a su prole» (p. 98). No extraña por ello un trato vejatorio semejante cuando el autor desaconseja el uso del sintagma «compañero sentimental»:

El sintagma «compañero sentimental» para referirse a la persona con quien se tiene relación íntima no hace honor a la realidad que describe, sino que es eufemismo innecesario que pretende evitar términos desprestigiados como los de «querido», «querida», «barragán», «barragana», «mantenido», «mantenida». [...] Por eso, es preferible decir «cónyuge de hecho», o sencillamente «novio», término que procede de novus = reciente, nuevo, y sirve para aludir a la frecuencia con que se cambia de acompañante (p. 99).

Ahora, además, la institución matrimonial se revelaría como el modelo recto de relación sentimental íntima. Elocuente por sí misma es la alusión a los términos con los que se trataría de sustituir al censurado por PCG; es imposible sustraerse a la transferencia, que la mención del autor promueve, del menosprecio con el que eran (¿son?) usados 'barragán’ o ‘querida' a la situación que se quiere describir con 'compañero sentimental'. La solución propuesta por PCG, para no caer en el eufemismo innecesario, parece encubrir un halago a las virtudes del matrimonio: de sus palabras parece desprenderse que este tipo de vinculación contractual vendría a ser una salvaguarda contra la promiscuidad a la que conducirían los otros tipos de uniones no sujetas a regulación matrimonial.

Por otro lado, el autor sugiere, sorprendentemente, que el término 'moro' no es despectivo (p. 150), basándose en que es un término anterior al Islam, usado por los romanos y por San Isidoro. Es obvio que tal pretendida justificación no tiene sentido, pues la realidad de aquellos tiempos no tiene nada que ver con la realidad actual ${ }^{11}$.

En lo que respecta a aspectos lingüísticos, el tratamiento de PCG no es más afortunado. Una de las cuestiones que sin duda llaman más la atención es su consideración del cambio lingüístico. Por un lado, señala que las lenguas no son trajes a medida, pues «el hablante evoluciona y es a lo largo de los años» (p. 17), de modo, sigue señalando, que no es lo mismo por ejemplo el habla riojana de hoy que el habla del siglo XIX. Sin embargo, por otro lado podemos leer con verdadero asombro las siguientes palabras al respecto de los supuestos errores del lenguaje, y de la consiguiente necesidad de preservar el idioma:

Conviene sacar aquí a colación lo que Probo, en plena descomposición del latín, escribía a modo de advertencia, censurando el uso descuidado que de la lengua clásica se hacía:

10 Los tres argumentos que el autor esgrime contra este tipo de usos dobles son la conciencia etimológica, la falsa creencia de que el género gramatical es inherente al sexo de la cosa nombrada y finalmente que el concepto de género se diluye a favor del valor semántico referido a la generalidad (cf. pp. 98, 103, 104 y 114).

11 Por cierto que en relación al Islam, PCG tiene unas palabras también sorprendentes, pues señala, en referencia a antiguas sedes apostólicas situadas en países islámicos, que esas sedes están en «países ocupados por los infieles» (p. 206). Como se puede apreciar, el autor del libro usa un lenguaje más propio del tiempo de la Reconquista. 
«Dígase calida, no calda; vetulus, no veclus; auris, no oricla...'». No hicieron caso a aquel buen gramático y el latín vulgarísimo acabó con la lengua áurea de forma anárquica, a espaldas de la conveniente presencia del orden normativo en la vorágine de una evolución lingüística desatada (p. 12).

Mediante estas sorprendentes palabras, lo que hace el autor es sencillamente tratar de negar la legitimidad de la evolución histórica de las lenguas. Para rebatir tal opinión, baste sencillamente con señalar que si, como sugiere el autor, se le 'hubiera hecho caso' a Probo, no se hubiera producido el desarrollo evolutivo que condujo a la aparición y el desarrollo de todas las lenguas románicas, derivadas no de ese 'latín áureo', sino del 'latín vulgarísimo'. En suma, gracias a ese 'no hacer caso' a Probo, surgieron catalán, francés, italiano, portugués, gallego, etc., además del propio castellano, que con tanto ahínco trata este autor de defender con respecto a supuestas corrupciones, y que no hubiera existido si no fuera precisamente por esa evolución. De ahí el antes referido carácter sorprendente de la tesis de PCG. En todo caso, aunque este autor es más radical o vehemente a la hora de denigrar el cambio lingüístico, tal idea no deja de ser común entre aquellos que se aferran a la perspectiva purista: dado que hay que preservar como sea una variedad concreta, como es el estándar, tal perspectiva se caracteriza por un profundo inmovilismo, en el que cualquier desvío de la referida variedad debe ser severamente reprimido para evitar la 'corrupción' de la lengua, con lo que se veta por principio cualquier evolución. Clark e Ivanic (1997: 188-189) lo expresan claramente: «those who complain about falling standards are resistant to language change, assuming that forms should not change over time». Es realmente paradójico que esa perspectiva purista pretenda quitar legitimidad a un proceso natural, como la evolución y el cambio lingüísticos, para intentar darle tal legitimidad a un proceso claramente artificial, como es el predominio de una variedad sobre el resto de ellas. Por citar un mero ejemplo, PCG señala que 'enfatizar' no existe en castellano con el valor de recalcar o acentuar, por lo que no es correcto usar tal verbo de ese modo (p. 145). No obstante, una cosa es lo que pretende este autor, y otra bien diferente lo que sucede en esa lengua real, la cual, bien que le pese a PCG, existe; en ella, 'enfatizar' ciertamente existe, en tanto que es usado. Pero en este sentido es chocante que en otro lugar el autor escriba que «la lengua, sin sus hablantes, es nada» (p. 35). Si efectivamente la lengua sin sus hablantes es nada, no se entiende por qué el libro ignora de manera sistemática a los hablantes, tachándolos de mostrencos y otros calificativos, cuando adoptan soluciones que no pertenecen a una variedad en gran medida artificial como el estándar. Por ello, PCG es buen exponente del (dicen que muy hispánico) «a Dios rogando y con el mazo dando».

Otra obsesión presente en bastantes pasajes del libro es el evitar lo innecesario, las redundancias o pleonasmos, contempladas como un vicio presente en todas las lenguas (p. 72) y que es demonizado. Por ejemplo, PCG escribe: «Aprovecho para aconsejar la conveniencia de huir de las perífrasis verbales [...]: cuando hay un verbo para expresar una acción, es preferible usar ese verbo y dejarse de rodeos» (pp. 43-44; cf. también p. 81), y sigue señalando que «Lo ideal es decir las cosas con las palabras justas, en eso reside la pureza del lenguaje, a menos que queramos hacer literatura» (p. 44; sobre esta drástica separación entre lenguaje literario y no literario, cf. infra). A tal 'vicio' incluso le aplica nuestro autor las nociones de corrección e incorrección que impregnan el libro, si bien de manera arbitraria, carente de criterio: por ejemplo, señala (p. 72) que 'subir arriba' es un pleonasmo correcto, igual que 'salir afuera', 'entrar dentro', etc. Por el contrario, una oración como 'El reglamento está en 
vigor actualmente' sería incorrecta en tanto que 'actualmente' sobra, pues el propio verbo ya introduce la idea de presente; uno se pregunta, a este respecto, si 'subir' puede introducir otra noción que la de 'arriba', o si 'salir' puede relacionarse con otra noción diferente de la de 'fuera' (del estilo de 'subir abajo', 'salir dentro' o 'entrar fuera'). En todo caso, debe notarse que el autor del libro cae en muchas ocasiones, de manera contradictoria con sus propias asunciones, en esas redundancias que rechaza tan tajantemente, como cuando alude a «los partidarios del club de fútbol madrileño Real Madrid» (p. 93), o como cuando escribe que lo correcto es decir «El equipo X se hizo acreedor a la Copa del Rey en la modalidad o apartado de baloncesto» (p. 193). ¿Dónde está, en ejemplos como los citados, la economía lingüística que pregona?

Según PCG, «El hablante culto utiliza las palabras justas: es el sello de quien verdaderamente posee competencia lingüística» (p. 171). Estas palabras se comentan a sí mismas, pues la competencia lingüística (conocer una lengua, con todo lo que esto implica) es algo bien diferente de 'usar las palabras justas' y, por supuesto, tal competencia no es patrimonio exclusivo de los hablantes cultos (nótese, al tiempo, que la división efectuada entre hablantes cultos y no cultos no es un atributo intrínseco a personas, sino que depende de las situaciones). En realidad, si se hiciera caso a este autor, la comunicación no sería viable, pues, como la lingüística ha dejado bien establecido desde hace ya mucho tiempo, las redundancias no son 'rasgos que entorpecen el mensaje y hacen que el discurso resulte farragoso', parafraseando unas palabras del autor (p. 170), sino que son absolutamente necesarias para sobreponerse al ruido (en el sentido de la teoría de la información); el lenguaje real no puede funcionar sin redundancias, de manera que:

La redundancia en variadas formas es una necesidad básica de la comunicación lingüística. En realidad, la naturaleza humana es tal que una eliminación total de la redundancia podría, en muchas circunstancias, acarrear un serio incremento de la energía gastada al hablar (Martinet, 1962: 184)

una lengua sin redundancia sería absolutamente indescifrable, puesto que la aparición en ella de un elemento sería aleatoria. Tampoco podrían adquirirla los niños, puesto que se aprende a manejar una unidad nueva fundamentalmente gracias a su aparición en contextos conocidos que permiten comprender su sentido, lo que sería imposible si los sentidos de las unidades que la rodean no redujesen la incertidumbre relativa a la de la unidad considerada (François, 1969: 340)

En consecuencia, el llamamiento de PCG a ser cartujos lingüísticamente hablando es una entelequia $^{12}$.

Parcialmente relacionado con esa obsesión a no decir ni una palabra de más (algo que ni el propio PCG respeta, como hemos apreciado) está la separación tajante que establece entre el lenguaje no literario y el literario, de modo que ciertos rasgos, como el pleonasmo o redundancia, entre otros, son incorrectos en el primero, justificándose solamente en el segundo.

12 Pero asumida demasiado literalmente por el autor; por ejemplo, en las pp. 186-187 discute, en referencia a los teléfonos, si se debe utilizar 'móvil' (o 'móbil') frente a 'portátil', señalando que es preferible utilizar 'portátil', si bien «en contra de esta propuesta está el hecho de que es voz que tiene más sílabas, lo que va en contra de la economía lingüística». No sabemos si tal concepción se pretende erigir sobre la perspectiva de economía de Martinet; si así fuera, PCG ha entendido de manera completamente equivocada al autor francés. 
Esta concepción es muy clara en las siguientes palabras: «Lo ideal es decir las cosas con las palabras justas, en eso reside la pureza del lenguaje, a menos que queramos hacer literatura» (p. 44). De este modo, por ejemplo las perífrasis «sólo están justificadas en retórica con fines expresivos determinados, o en la literatura para embellecer el lenguaje» (p. 81), no debiendo emplearse «en el lenguaje expositivo ni en el discurso habitual» (p. 81), mientras que la moda de acortar palabras «sólo es lícita [...] cuando persigue fines literarios» (pp. 74-75). Por citar otro caso, podemos leer que «el uso figurado [de 'amainar'; VML y JJLR] puede explicar otros destinos significativos admitidos para este verbo, pero el abuso del sentido metafórico desvirtúa la licitud de esa práctica cuando lo importante es informar y no hacer literatura» (p. 54). Tal concepción causa que considere los usos figurados como apropiaciones semánticas indebidas o robos semánticos (cf. p. 317).

Todo ello caracteriza una concepción curiosa de lo que es el lenguaje: o informar o hacer literatura. En lo que respecta a las metáforas, es muy claro que el autor todavía sostiene la concepción tradicional según la que la metáfora es una mera figura retórica o artificio (de ahí la calificación de 'robo semántico' que efectúa PCG), y se inscribe en un uso 'marcado' o no natural del lenguaje. El autor parece desconocer el trabajo de autores como George Lakoff (cf. Lakoff y Johnson, 1980; Lakoff y Turner, 1989, por restringirnos a dos obras clásicas) sobre la centralidad de las metáforas en el lenguaje cotidiano, y, más en general, en los procesos cognitivos subyacentes ${ }^{13}$.

Pero, más allá de su consideración muy antigua y rancia de las metáforas, la separación drástica que postula entre lenguaje cotidiano y literario es insostenible. Restringiéndonos a unos pequeños apuntes al respecto, PCG juzga los usos 'buenos' o 'malos' no en sí mismos, sino según quién los use y según el contexto de uso. En este sentido, una buena pregunta al respecto sería: un uso admisible dentro de la literatura, ¿se transformaría en un uso incorrecto cuando fuera empleado por un literato fuera de las labores creativas, esto es, fuera de su profesión? Según la concepción del libro, un mismo uso de una misma persona es unas veces un uso 'mostrenco' y otras veces no: por ejemplo un autor literario utiliza determinado rasgo en una obra, el cual no puede ser tachado de mostrenco, pero si utiliza ese mismo rasgo en el lenguaje no literario, resulta que ya sería un rasgo mostrenco, o un vicio, como la redundancia. ¿O acaso el autor pretende que alguien, por ser escritor, por dedicarse profesionalmente a la literatura, está a salvo (esto es, sería inmune de ser juzgado) de hacer usos 'mostrencos' del idioma, sea cual sea el contexto en que ejerza tales usos? Por otro lado, es obvio que si esos usos se encuentran también fuera de la literatura, no son creaciones literarias. Además, ¿cómo se le enseñaría a un niño que no utilice un uso dado, por ser 'mostrenco', si se puede encontrar con ese uso en un texto literario? Por tanto, el autor del libro parece otorgar patentes de corso lingüísticas: hay personas, sencillamente, que pueden hacer con el idioma lo que les apetezca, mientras que el resto de los mortales no podemos. PCG parece practicar

13 Una vez más, PCG no se aplica para sí lo que defiende para los demás, pues su libro está repleto de esos 'robos semánticos' o 'sentidos figurados' que a su juicio deberían estar restringidos al ámbito literario. Sirvan unos pocos ejemplos: «ola gigante de mal decir» (p. 12), «se siembra la semilla de la incorrección» (p. 13), «el uso figurado explica destinos significativos admitidos [...]» (p. 54), «no resbalar hacia el error» (p. 70), «dilatando su vida fónica [del discurso; VML y JJLR] sin necesidad» (p. 173), «El equipo X se hizo acreedor a la Copa del Rey [...]» (p. 193), etc. 
juicios sociales, más que juicios lingüísticos, efectuando una clara discriminación social: los literatos, que no son mostrencos, y los demás, mostrencos.

Por otro lado, los criterios que maneja el libro son muy oscuros. Un ejemplo ilustrará tal aspecto: el autor sostiene que el castellano tiene gran riqueza expresiva, si bien «no cabe decir lo que uno quiera, ya que todo ha de estar consagrado, al menos, por el uso» (p. 101). Sin embargo, la perspectiva sostenida por el libro no permite que nada que se aparte del estándar pueda 'consagrarse', de modo que si algo está realmente consagrado por el uso, pero no se acoge al estándar, se le tilda de uso mostrenco, barbarismo, incorrección, etc. (como en el caso, ya señalado, de 'enfatizar'). Téngase en cuenta que consagrado por el uso implica automáticamente consagrado por los hablantes, pero es obvio que esto no sirve para PCG.

En el fondo, la práctica totalidad de los aspectos problemáticos señalados en el libro derivan de su consideración de que el estándar es la variedad correcta o superior, la única que debe ser usada, mientras que el resto de variedades son, usando una calificación muy del gusto de PCG, mostrencas, siendo denigradas sistemáticamente. Moreno Cabrera (2000: 246-248) ha caracterizado a la perfección las diferentes asunciones que subyacen a la consideración del estándar como modelo único, excluyente, de lengua, y del resto de variedades como inferiores o incorrectas. No por casualidad, la práctica totalidad de tales asunciones son claramente sostenidas por PCG:

- La lengua estándar es mejor y más perfecta que otras variedades de lengua

- Los dialectos son más inestables, incultos y pobres que las lenguas

- Las variedades no estándares carecen de gramática y, por tanto, son incorrectas

- La pureza lingüística debe ser una cualidad de la lengua estándar

Pues bien, esas ideas sobre la in/corrección de variedades, ¿están realmente justificadas desde la óptica puramente lingüística, que es la única que las podría legitimar, o más bien responden a otro tipo de razones que no tienen que ver con esa óptica? En otras palabras, ¿se puede sostener realmente que una variedad no estándar supone corromper o deturpar el idioma, o, en palabras del autor del libro, 'engolfarse en prácticas mostrencas'? La respuesta es clara: esas ideas sobre la superioridad o corrección del estándar de ningún modo se justifican desde la perspectiva lingüística, por lo que son un claro ejemplo de prejuicio lingüístico. Sobre todo porque, históricamente, el estándar no es otra cosa que un dialecto más, que por razones bien diferentes de las lingüísticas ha sido potenciado artificialmente.

Vamos a ejemplificar con un fenómeno (de entre los muchos que se podrían elegir) que el autor tacha de incorrecto: la colocación pronominal del estilo de 'te se nota' en lugar de 'se te nota', usual en el castellano de Castilla, Cantabria o Canarias, y que PCG considera 'vulgarismo' (p. 162). Es cierto que tal colocación no es la extendida entre bastantes hablantes de castellano, de modo que puede sonar rara a los que no hablan dialectos que la poseen. Sin embargo, para sostener que esa colocación es incorrecta, o vulgar, es obvio que no basta con decir que suena mal o rara, o mucho menos aún, que es anómala sencillamente porque no es la colocación propia del estándar (lo cual sería un razonamiento puramente circular). En suma, para tratar de justificar la incorrección, desde premisas puramente lingüísticas, de esa colocación, PCG tendría que mostrar que tal colocación es, en algún sentido lingüístico o comunicativo, inferior al modelo alternativo de colocación ('se te nota'). En otras palabras, tendría que demostrar que hay diferencias lingüísticas o comunicativas en sentido 
amplio asociadas al uso de uno u otro orden de colocación, con respecto a preguntas como las siguientes:

- Ese orden de colocación supuestamente vulgar, ¿es comunicativamente menos eficiente que el orden supuestamente 'correcto'?

- ¿Implica la pérdida de alguna característica semántica que sin embargo es satisfecha por o plasmada en la versión 'correcta'?

- En la misma medida, ¿supone la pérdida de algún rasgo o distinción gramatical?

- Mediante ese orden 'vulgar', ¿se entorpece la efectividad del enunciado?

- ¿Produce ambigüedad, o la favorece, frente a la versión 'correcta'?

- En general, el orden 'te se nota', ¿supone alguna pérdida o merma en el poder expresivo general de las secuencias que adoptan tal colocación?

Es importante tener en cuenta que es únicamente el tipo de preguntas señaladas el que justificaría realmente que ciertos rasgos son 'inferiores' y otros 'superiores' desde una perspectiva lingüística. Se podrían seguir formulando más preguntas de ese estilo, pero las apuntadas son suficientes para apreciar que la respuesta a todas ellas es un rotundo 'no': no hay manera de asociar esa colocación supuestamente 'incorrecta' con ningún tipo de efectos lingüísticos anómalos. Por tanto, el orden de estilo 'te se nota' es, simplemente, diferente del orden 'se te nota', pero, y esta es la clave, esa diferencia no implica ni justifica la inferioridad, incorrección o carácter 'mostrenco' de un rasgo como el señalado. Las siguientes palabras de Moreno Cabrera (2000: 247-248) son muy elocuentes al respecto (cf. también Longa, 2008):

La gramática estándar del español obliga a considerar correcto 'se me cayó' frente al incorrecto 'me se cayó'. Pero la secuencia 'me se' es tan posible e impecable gramaticalmente como 'se me' (de hecho, el italiano opta por ella). Nada hay en la gramática que nos diga que la secuencia 'me se' está mal. Simplemente, hay una regla de orden de pronombres clíticos con dos formulaciones. Una de ellas es la de la lengua estándar, pero podría perfectamente haber sido la otra.

No hay, pues, razones lingüísticas que permitan considerar al estándar una variedad superior al resto, ni sostener la superioridad intrínseca de los rasgos de tal variedad frente a los rasgos del resto de variedades. Lo que desde la perspectiva purista, prescriptiva, motiva la consideración de determinados rasgos como incorrecciones, vicios, etc., no es más que el hecho de que se apartan del modelo de lengua exclusivamente representado por el estándar, y que en consecuencia condiciona a la hora de juzgar. Y tal situación tiene una gran fuerza, ya que se retroalimenta: dado su gran prestigio, suele ser la única variedad recogida en gramáticas, manuales de estilo, libros de texto, diccionarios, etc., así como la única variedad usada en muchos e importantes ámbitos, como justicia, educación, legislación, administración, política, ciencia o literatura. De ese modo, el estándar se erige en la única variedad visible a los ojos de la sociedad, con lo que su prestigio sigue aumentando en la misma medida en que aumenta el desprestigio del resto de variedades. Y como el resto de variedades no se usan en esos ámbitos, se asocian con versiones degeneradas, corruptas o mostrencas del estándar, indignas de ser recogidas por escrito. De hecho, por ejemplo, un título como 'Gramática española' o 'Gramática inglesa' no es nunca un manual sobre la lengua española o inglesa, 
sino solamente sobre la variedad estándar (de nuevo, tenemos aquí la falacia de la parte por el todo $)^{14}$. En suma, el razonamiento para sostener el carácter superior del estándar es puramente circular: un rasgo $\mathrm{X}$ es correcto, o mejor, que otro rasgo Y porque pertenece al estándar, y como pertenece al estándar, es correcto o mejor. Es así de sencillo, y, por desgracia, el libro comentado se hace cómplice (y muy vehemente) del mantenimiento de tal situación.

Si efectivamente el carácter 'superior' del estándar no es sostenible desde criterios estrictamente lingüísticos, eso significa que el estándar es una variedad (bien geográfica, bien social) como cualquier otra, una simple variedad más, que alcanzó una posición de predominio (claramente abusiva) de manera arbitraria, esto es, por razones extralingüísticas, vinculadas normalmente al prestigio o poder de una zona geográfica concreta o de un grupo concreto. Tal como escribe Moreno Cabrera (2008: 91), «una lengua estándar no es más que una versión elaborada en algunos puntos concretos de un determinado dialecto». Y a la pregunta de cuál es ese dialecto, la respuesta es igualmente nítida: «la variedad del estamento dominante» (Moreno Cabrera, 2008: 75-76). En palabras de Fasold y Connor-Linton (2006: 7):

Not surprisingly, the language variety of that dominant group is often perceived as having
higher status as well, especially if speaking it affords increased access to power or wealth.
By comparison, the language varieties spoken by the less powerful groups often are stigma-
tized as 'incorrect' or 'bad' language. ${ }^{15}$

En suma, una variedad se convierte en estándar por razones históricas casi siempre. Por ejemplo, el estándar castellano deriva de la variedad hablada en Castilla, que fue una zona muy importante políticamente (cf. Penny, 2000). Por su parte, la variedad erigida en inglés estándar no por casualidad es la que se hablaba en la zona centro-oriental del país, la más importante en riqueza, población, cultura y poder, pues en ella estaba Londres, además de los importantes focos culturales de Cambridge y Oxford. En igual medida, el francés estándar se basa en el franciano, dialecto local de la Isla de Francia, zona en la que estaba París, ciudad de gran preponderancia. Como último ejemplo, lo mismo se aplica al caso italiano, cuyo estándar es el toscano, y dentro de él, el florentino: Florencia fue un foco muy importante, económica, política y culturalmente, en la Italia renacentista. Por ello, no debe extrañar que las variedades mencionadas en cada caso, y no otras, se convirtieran en el modelo a seguir. Pero de nuevo, debe notarse que en tal fijación las razones puramente lingüísticas brillan por su ausencia.

14 Otra falacia no menor es denunciada por Moreno Cabrera (2008), entre otros autores: frente a lo que la postura basada en la corrección de la lengua sostiene mediante una construcción ideológica muy fuerte y elaborada, los dialectos de una lengua no son dialectos del estándar, sino que el estándar es (o deriva de) un dialecto concreto. De hecho, según Milroy y Milroy (1991: 22-23) o Moreno Cabrera (2008: 55, 174), el estándar representa ante todo una ideología, algo obvio teniendo en cuenta su carácter ficticio.

15 A este respecto, conviene también reflejar las siguientes palabras de Penny (2000: 295): «Las variedades habladas por grupos política y económicamente poderosos son las únicas con probabilidades de ser seleccionadas como base de una lengua estándar. Asimismo, sólo tales grupos (o individuos) son capaces de imponer codificaciones particulares de la lengua y de asegurar que serán usadas en un número creciente de ámbitos. Del mismo modo, sólo los poderosos pueden promover la aceptación de la norma emergente, ya que únicamente ellos gozan de suficiente prestigio social como para provocar que otros grupos sigan sus preferencias lingüísticas». Como se puede apreciar en las palabras de Fasold y Connor-Linton y de Penny, la elección del estándar nada tiene que ver con criterios puramente lingüísticos. 
Las conclusiones deberían ser diáfanas: un estándar, en suma, lo ha llegado a ser por razones que no son en absoluto lingüísticas, sino extralingüísticas, de índole arbitraria, por la pujanza o poder de áreas o de grupos concretos. Si las circunstancias hubieran sido otras, el estándar de cada una de las lenguas señaladas en el párrafo previo sería otro diferente, aquel que perteneciera a la zona (o grupo) hegemónica. A pesar de ello, la estrategia argumentativa de PCG consiste en silenciar ese hecho, tratando de hacer pasar por lingüísticas razones que no tienen nada que ver con ellas a la hora de poner al estándar en el pedestal erigido por el prescriptivismo. Precisamente, como señala Moreno Cabrera (2008: 43), determinados conceptos, como el de estándar, son usados «para construir un discurso que busca fundamentar determinadas ideologías que intentan llevar al terreno de la evolución puramente lingüística fenómenos que son claramente extralingüísticos y que no tienen nada que ver con las leyes propias del cambio gramatical». De ahí que, según este mismo autor (Moreno Cabrera, 2000: 48):

El hecho de que se produzca un proceso de estandarización de una variedad determinada no se debe en modo alguno a que ese dialecto sea en un sentido u otro superior o más excelso que los demás, sino a una serie de procesos extralingüísticos que tienen que ver muy a menudo con el dominio que un determinado grupo social, político, cultural o económico ejerce sobre otros grupos ${ }^{16}$.

Por tanto, dado que «standard forms are not better than other forms» (Fasold, 2006: 379) y que «No existe un dialecto que pueda ser considerado mejor que otro» (Tusón, 1996: 89), la conclusión consiste en que:

En términos lingüísticos, ningún dialecto de una lengua es más correcto, mejor o más lógico que cualquier otro dialecto de la misma. Todos los dialectos son formas igualmente eficaces de una lengua en el sentido de que cualquier idea que se exprese en uno de ellos podrá expresarse con la misma facilidad en el otro. La idea de que el inglés estándar, o una determinada realización del castellano, sean las formas correctas de sus respectivas lenguas es una actitud social -más precisamente, un prejuicio lingüístico- que es tan irracional como los prejuicios sociales contra la raza o el sexo [...]. En definitiva, es importante darse cuenta de que llamar estándar a un determinado dialecto e inferior a los otros refleja un juicio sociopolítico y no un juicio lingüístico (Akmajian, Demers y Harnish, 1979: 223).

La óptica sostenida por PCG no tiene, pues, fundamento lingüístico alguno ${ }^{17}$ : el estándar es un dialecto que, por razones de todo tipo menos lingüísticas (históricas, sociopolíticas,

16 Idéntica perspectiva es sostenida por autores como Akmajian, Demers y Harnish (1979: cap. 9), Bernárdez (1999: cap. 2), Clark e Ivanic (1997: 211), Coseriu (1986: 39-40), Fasold (2006), Fasold y Connor-Linton (2006), Ferreiro y Teberosky (1979: cap. 7), Longa (2008), Lyons (1981: 240), Romaine (1994: 107), Schilling-Estes (2006) o Tusón (1996: 90), entre otros muchos.

17 Y tal óptica es, si cabe, más sorprendente, en tanto que este autor por un lado parece reconocer la arbitrariedad de los procesos históricos, pero por otro defiende continuamente el carácter superior del estándar. De hecho, este autor escribe que «lo que llamamos «lenguas de cultura», como el castellano o el francés, fueron en sus comienzos modestísimos dialectos [...]. Son puras vicisitudes históricas las que favorecieron a unos y perjudicaron a otros» (p. 35). Por ello, es un contrasentido que intente ocultar esas mismas razones históricas, arbitrarias, a la hora de atribuir 
culturales, etc.) ha adquirido una posición de privilegio dentro del conjunto de variedades de una lengua.

Todo lo dicho no implica negar la utilidad (e incluso la necesidad) de la existencia de una variedad estándar; de hecho, tal variedad tiene asociadas funciones ventajosas, como especialmente su papel de subcódigo común, que permite salvar las diferencias existentes entre las variedades de una lengua, garantizando así una intercomprensión plena o marco comunicativo común entre los hablantes (téngase en cuenta que tal intercomprensión no siempre es fácil, y para apreciar esto no hace falta salir del castellano), traducible también en ámbitos como la educación, justicia, administración, etc. Pero esas ventajas rigen siempre y cuando el estándar sea valorado en su justa medida en lugar de sobrevalorado, y valorarlo así supone reconocer que su valor es puramente instrumental en lugar de intrínseco; en otras palabras, siempre que se relativice su valor, no asumiendo acríticamente que el estándar, por serlo, es superior, más correcto o mejor que el resto de variedades. Lamentablemente, la perspectiva representada por PCG se caracteriza por ir mucho más allá del valor meramente instrumental del estándar, defendiendo por el contrario una superioridad intrínseca de tal variedad. Y cuando se cruza esa barrera, los beneficios asociados a la existencia de esa variedad se pierden, pues lo que se consigue es sencillamente discriminar y justificar la discriminación.

De hecho, señalamos antes que el menosprecio de las variedades no estándares no es el resultado más indeseable al que conduce la postura purista; dado que esas variedades no existen de manera abstracta, sino que son habladas por personas de carne y hueso, tal postura desemboca a la fuerza en discriminar o marginar a quienes usan variedades no estándares ${ }^{18}$ : al sostener el carácter mejor o superior de una variedad también se sostiene automáticamente el carácter superior de aquellos que la utilizan. Por ello, colocar en un pedestal al estándar provoca a menudo situaciones de discriminación lingüística (y social) hacia los hablantes del resto de variedades, como señalan Fasold y Schilling-Estes (2006: 8):

One consequence of these kinds of language attitudes -in which one language variety is considered better than others- is the corollary belief that speakers of «incorrect» varieties are somehow inferior, because they will not or cannot speak «correctly». Their «incorrect» language is then used to justify further discrimination -in education and in employment, for example. Discrimination on the basis of language use in based on two false propositions: that one variety of language is inherently better than others, and that people can be taught to speak the 'correct' variety.

Creemos que esto es inadmisible, y a ello aludía nuestra apelación inicial a la responsabilidad de la lingüística profesional ante la sociedad, que no debería dejar de desentrañar críticamente y denunciar ese tipo de construcciones ideológicas que favorecen la desigualdad lingüística, social, y en general, humana. Por ello, las ideas que PCG representa son de lamentar, por asimétricas y antidemocráticas, pues sostienen y reproducen una profunda desigualdad entre variedades y también (lo que es peor) desigualdad y discriminación entre

un carácter correcto o superior al estándar, denigrando al resto de variedades. De nuevo se aprecia la falta de criterio que es una constante en todo el libro.

18 Por ello, es paradójico que PCG afirme que «la lengua, sin sus hablantes, es nada» (p. 35). Más bien, este autor debería escribir que la lengua, sin los hablantes del estándar, es nada, afirmación que estaría en sintonía plena con la ideología y los contenidos del libro. 
hablantes, todo lo contrario de los valores que deberían imperar en una sociedad supuestamente democrática: «Un elitista entiende la expresión [...] centrada en los valores de las élites y en la negación implícita de los valores populares. El culto de la sintaxis dominante y el repudio, como fealdad y corrupción, de la prosodia, la ortografía y la sintaxis populares» (Freire, 1993: 47). Téngase en cuenta que los procesos de estandarización, y los resultados a los que conducen, son uno de los principales agentes de desigualdad, pues, en palabras de Romaine (1994: 107), «el objetivo es terminar con la variación y establecer un sistema único y uniforme para todo un grupo social».

De ese modo, una variedad usada por un grupo de poder se impone sobre el resto de variedades y las estrangula, o lo que es lo mismo, un grupo determinado impone sus costumbres e ideologías sobre todos los demás. Nótese la profunda desigualdad de tal proceder: todas las sociedades, y especialmente las actuales, dada su enorme complejidad, están conformadas por un espectro muy heterogéneo, pues se componen de muchos grupos que se caracterizan por ideologías, intereses y aspiraciones muy diferentes en cada caso. Pero como apuntan Clark e Ivanic (1997: 21, 55), no todas esas ideologías e intereses se hacen visibles; más bien, sólo llegan a serlo aquellas que pertenecen a los grupos dominantes (cultural, política, social o económicamente), con el resultado de que las reclamaciones, anhelos o ideologías del resto de grupos son marginadas y a la postre silenciadas. Es bien conocido el papel tan importante del lenguaje al respecto, al ser un mecanismo central de poder y control, y lo señalado se aplica paradigmáticamente a la cuestión del estándar y de sus implicaciones ideológicas: una variedad dada, perteneciente (tanto diacrónica como sincrónicamente) a las clases dominantes, se impone al resto de variedades, de manera que estas son desacreditadas e invisibilizadas de manera arbitraria e irracional, siendo tildadas de incorrectas, vulgares o 'mostrencas' cuando en realidad tales variedades forman parte del español de pleno derecho (de hecho, forman parte del español con mayor razón que el propio estándar, dado que sobre este han actuado procesos artificiales). Y la construcción ideológica implicada es clara, como sugiere Moreno Cabrera (2008: 59): «Esos intereses particulares de una determinada etnia se presentan como intereses de toda la sociedad pluricultural y plurinacional y se utilizan para presionar, marginar y mantener en una posición de subordinación a las etnias minoritarias o no dominantes». De ahí que los usuarios del estándar se sitúen en una posición de privilegio, predominio y poder con respecto a los hablantes de otros dialectos, provocando una clara asimetría y desigualdad al respecto que se plasma en restar oportunidades a quienes no se someten a tal esquema.

Lamentablemente, el libro de PCG no hace sino ayudar a mantener y reproducir la situación señalada, muy injusta tanto lingüística como socialmente: al marginar irracionalmente (sin ninguna razón estrictamente lingüística) toda variedad no estándar, no sólo asume y reproduce esa desigualdad y ese carácter antidemocrático lingüística y socialmente, sino que (y esto es lo más chocante) pretende justificarlo con total naturalidad. Por ello, la perspectiva de PCG es profundamente desafortunada: en su libro el respeto a los hablantes y a la variación lingüística brilla sencillamente por su ausencia. 


\section{Referencias bibliográficas}

Akmajian, A., R. Demers y R. Harnish (1979): An Introduction to language and communication. Cambridge, MA, MIT Press. Cit. por la trad. de V. Demonte y M. Mora: Lingüistica: una introducción al lenguaje y la comunicación. Madrid, Alianza, 1984.

Alcaraz Varó, E. y Mª.A. Martínez Linares (1997): Diccionario de lingüistica moderna. Barcelona, Ariel.

Bernárdez, E. (1999): ¿Qué son las lenguas? Madrid, Alianza.

Celdrán Gomariz, P. (2006): Hablar con corrección. Normas, dudas y curiosidades de la lengua española. Madrid, Temas de Hoy.

Clark, R. y R. Ivanic (1997): The politics of writing. London, Routledge.

Coseriu, E. (1986): Introducción a la lingüistica. Madrid, Gredos.

Fasold, R. (2006): «The politics of language». En Fasold, R. y J. Connor-Linton (eds.), págs. 373-400.

Fasold, R. y J. Connor-Linton (2006): «Introduction». En Fasold, R. y J. Connor-Linton (eds.), págs. $1-11$.

Fasold, R. y J. Connor-Linton (eds.) (2006): An introduction to language and Linguistics. Cambridge, Cambridge University Press.

Ferreiro, E. y A. Teberosky (1979): Los sistemas de escritura en el desarrollo del niño. 14ª ed. Méjico, Siglo XXI, 1993.

François, F. (1969): «Redondance». En Martinet, A. (dir.): La Linguistique, Guide alphabétique. Paris, Denoël, págs. 330-335. Cit. por la trad. de C. Manzano, «Redundancia», en La lingüística. Guía alfabética. Barcelona, Anagrama, 1972, págs. 338-343.

Freire, P. (1993): Politica e educaçao. Sao Paulo, Cortez Editora. Cit. por la trad. de S. Mastrángelo: Política y educación. $2^{\mathrm{a}}$ ed. Méjico, Siglo XXI, 1997.

Gómez Torrego, L. (2002): Nuevo manual de español correcto. Vol. I. Acentuación, puntuación, ortografia, pronunciación, léxico, estilo. Madrid, Arco/Libros.

Grijelmo, Á. (2006): La gramática descomplicada. Madrid, Taurus.

Joseph, J. (2006): Language and politics. Edinburgh, Edinburgh University Press.

Lakoff, G. y M. Johnson (1980): Metaphors we live by. Chicago, University of Chicago Press. (Trad. de C. González, Metáforas de la vida cotidiana. Madrid, Cátedra, 1986).

Lakoff, G. y M. Turner (1989): More than cool reason. A field guide to poetic metaphor. Chicago, University of Chicago Press.

Lázaro Carreter, F. (1997): El dardo en la palabra. Barcelona, Galaxia-Gutenberg y Círculo de Lectores.

Lázaro Carreter, F. (2003): El nuevo dardo en la palabra. Barcelona, Santillana y Círculo de Lectores.

Longa, V.M. (2008): «Sobre prejuicios lingüísticos y la necesidad de desterrarlos del ámbito educativo: dialecto estándar y dialectos no estándares», Aula de Encuentro, 11, págs. 167-186.

Lyons, J. (1981): Language and Linguistics. Cambridge, Cambridge University Press. Cit. por la trad. de R. Cerdá: Introducción al lenguaje y a la lingüistica. Barcelona, Teide, 1984.

Martinet, A. (1962): A functional view of language. Oxford, Clarendon Press. Cit. por la trad. de $M^{a}$.R. Lafuente: El lenguaje desde el punto de vista funcional. Madrid, Gredos, 1971.

Milroy, J. y L. Milroy (1991): Authority in language. Investigating language prescription and standardisation. London, Routledge.

Moliner, Ma . (2007): Diccionario de uso del español. 2 vols. $3^{\mathrm{a}}$ ed. Madrid, Gredos.

Moreno Cabrera, J.C. (2000): La dignidad e igualdad de las lenguas. Crítica de la discriminación lingüistica. Madrid, Alianza.

Moreno Cabrera, J.C. (2008): El nacionalismo lingüístico. Una ideología destructiva. Barcelona, Península.

Muro, M.A. (1990): La gramática normativa. Fundamentos, práctica y perspectivas. Logroño, Gobierno de La Rioja e Instituto de Estudios Riojanos. 
Penny, R. (2000): Variation and change in Spanish. Cambridge, Cambridge University Press. Cit. por la trad. de J. Sánchez: Variación y cambio en español. Madrid, Gredos, 2004.

Real Academia Española (2001): Diccionario de la lengua española. 2 vol. $22^{\mathrm{a}} \mathrm{ed}$. Madrid, Espasa-Calpe. Romaine, S. (1994): Language in society. Oxford, Oxford University Press. Cit. por la trad. de J. Borrego: El lenguaje en la sociedad. Una introducción a la sociolingüistica. Barcelona, Ariel, 1996.

Schilling-Estes, N. (2006): «Dialect variation». En R. Fasold y J. Connor-Linton (eds.), págs. 311-341.

Tusón, J. (1996): Los prejuicios lingüísticos. Barcelona, Octaedro. 